\title{
Y Tizoma \\ Pathé-Baby e o horizonte técnico dos anos 1920
}

Resumo: Este trabalho objetiva relacionar o aprimoramento técnico do final século XIX e início do século XX com o universo literário brasileiro do mesmo contexto, com ênfase na obra Pathé-Baby, de António de Alcântara Machado. Com isso, busca-se estreitar os laços entre a arte literária e o arcabouço histórico, encontrando, na obra, elementos estéticos que remetam à telegrafia, à fotografia e, notadamente, ao cinema e todo o seu conjunto de procedimentos operacionais que transformaram o século XX.

Palavras-Chave: Pathé-Baby. Técnica. Anos 1920.

\section{Pathé-Baby y el horizonte técnico de los años 1920}

Resumen: Este trabajo objetiva relacionar el perfeccionamiento técnico del siglo XIX y principios del siglo XX con el universo literario brasileño del mismo contexto, con énfasis en la obra Pathé-Baby, de António de Alcántara Machado. Con ello, se busca estrechar los lazos entre el arte literario y el armazón histórico, encontrando, en la obra, elementos estéticos que remiten a la telegrafía, a la fotografía y, en particular, al cine y todo su conjunto de procedimientos operativos que transformaron el siglo XX.

Palabras-clave: Pathé-Baby. Técnica. Años 1920.

\section{Pathé-Baby and the technical horizon of 1920's}

Abstract: This paper aims to connect the technical development of the late nineteenth and early twentieth century with the Brazilian literary of the same context, with emphasis on the work Pathé-Baby, by António de Alcântara Machado. Thereby, the links between literary art and the historical framework will be strengthened, finding in the work aesthetic elements that refer to telegraphy, photography and, in particular, the cinema and all set of operational procedures that have transformed the twentieth century.

Keywords: Pathé-Baby. Technique. 1920'.

Lucas da Cunha Zamberlan 


\section{$\gamma_{\text {Rizoma }}$}

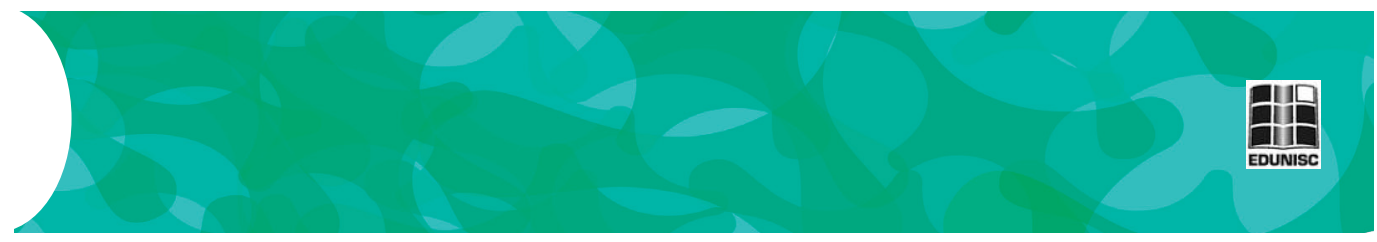

\section{Introdução}

Pathé-Baby é o livro de estreia do escritor António Alcântara Machado, publicado em 1926. O título constitui-se em uma alusão à popular câmera cinematográfica de $9,5 \mathrm{~mm}$ produzida pela Pathé Brothers Company, empresa de máquinas e produção cinematográfica, além de ser a produtora fonográfica de maior projeção no cenário mundial no final do século XIX e início do século XX.

Lançado um ano após o autor voltar da Europa, Pathé-Baby apareceu na coluna semanal do Jornal do Comércio, com o subtítulo "Panoramas Internacionais". Os textos acompanham a trajetória do autor no Velho Mundo, registrando cidades da França, Inglaterra, Itália, Portugal e Espanha com uma visão subjetiva engendrada, primeiramente, pela sua sensibilidade de artista e estetizada por uma técnica narrativa cinematográfica que se formata e se molda à projeção visual de uma câmera Pathé-Baby.

Com isso, este trabalho objetiva relacionar o intrincado aprimoramento técnico do final século XIX e início do século - e toda a sua influência no universo das mídias - com o universo literário brasileiro do mesmo contexto, com ênfase na obra Pathé-Baby, do escritor paulistano António de Alcântara Machado. Assim, buscase estreitar os laços entre a arte literária e o arcabouço histórico, encontrando, na obra, elementos estéticos que remetam à telegrafia, à fotografia e, notadamente, ao cinema e todo o seu conjunto de procedimentos operacionais que transformaram o século XX.

\section{A emulação dos processos operacionais do mundo mecanizado: o caso Pathé-Baby}

Flora Süssekind, em Cinematógrafo de letras (2006), analisa os caminhos que a literatura no Brasil percorreu, no final do século XIX e início do século XX, impulsionada pelo desenvolvimento da técnica como resultado do aprimoramento dos meios de comunicação e transporte. De forma geral, a autora comprova de que maneira os escritores da época, incluindo Alcântara Machado com Pathé-Baby, emularam os princípios mecânicos utilizados na manipulação das novas máquinas, gerando um repertório estético inédito, condizente com o panorama de uma sociedade cada vez mais automatizada.

A rigor, o objetivo do seu estudo é

sugerir uma história da literatura brasileira que leve em conta suas relações com uma história dos meios e formas de comunicação, cujas inovações e transformações afetam tanto a consciência de autores e leitores quanto as formas e representações literárias propriamente ditas. (SÜSSEKIND, 2006, p. 26). 


\title{
$\gamma_{\text {Rizoma }}$
}

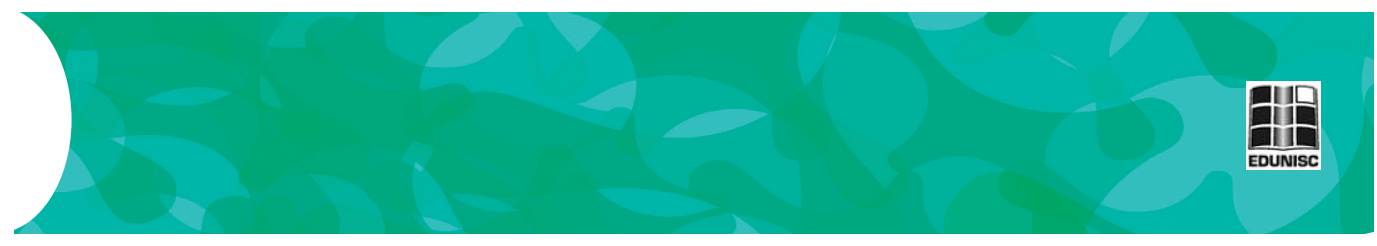

A operacionalização da arte literária enquanto estratégia narrativa ocorre, portanto, como uma consequência inelutável de um processo de transformação da sensibilidade dos produtores culturais situados no contexto delimitado pela autora. Como havia uma paulatina e irreversível mudança na maneira de os intelectuais interagirem com o universo da informação e com a própria sociedade, eles passaram, em maior ou menor grau, a mimetizar os recursos técnicos, fomentando um diálogo entre a prosa pré-modernista e modernista e procedimentos de origem mecânica. Pellegrini (2003), em concordância com Süssekind, aponta que

\begin{abstract}
As profundas transformações efetivadas nos modos de produção e reprodução cultural, desde a invenção da fotografia e do cinema - que alteraram, antes de tudo, as maneiras pelas quais se olha e se percebe o mundo -, estão impressas no texto literário. Tratando-se do texto ficcional, é a observação das modificações nas noções de tempo, espaço, personagem e narrador, estruturantes básicos da forma narrativa, que ajuda a entender um pouco melhor a qualidade e a espessura dessas modificações. (PELLEGRINI, 2003, p. 16).
\end{abstract}

Uma explicação plausível para o desencadeamento desse fenômeno, de ordem artística e social, é o número acentuado de invenções que começaram a fazer parte do cotidiano dos habitantes das grandes cidades. Mais especificamente, é possível sublinhar pelo menos uma dúzia de novidades, todas elas criadas e aperfeiçoadas, cronologicamente, entre 1850 e 1920. São máquinas, a maioria de uso doméstico, que reconstruíram toda uma maneira de se comportar, seja no espaço público ou privado. Na imprensa, locus comum entre os escritores do período, elas interferiram de maneira ainda mais categórica, modificando processos de criação e escrita.

A primeira e uma das mais notáveis invenções, em termos de influência no campo artístico, foi o telégrafo. Embora o sistema de telegrafia date do final do século XVIII, ele desenvolveu-se, à pleno, na segunda metade do século XIX, codificando mensagens que eram transmitidas a longas distâncias.

Alcântara Machado, como colunista do Jornal do Comércio, elegia seus comentários, amiúde, a partir de notícias que recebia via telégrafo. Uma delas, de dez de março de 1926, trata, com entusiasmo, de uma série de descobertas relativas à astronomia. $\mathrm{O}$ fato curioso fica por conta da referência a Edison, renomado inventor estadunidense, mentor da lâmpada incandescente, do fonógrafo e do cinescópio: 


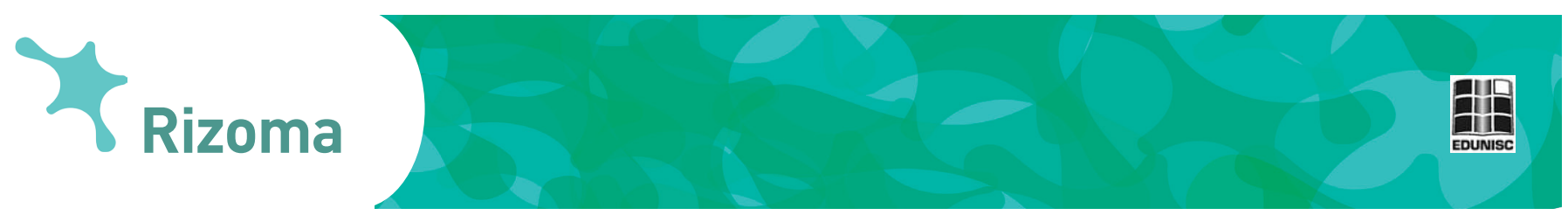

americano, de um universo. Sim: um novo universo, com astros, planetas, nebulosas e o mais do que necessita um universo que se preza...

O universo, que o patrício de Edison lobrigou pela lente do seu telescópio, está separado da terra por uma distância incrível. Basta dizer que a sua luz nos chega, aproximadamente, com setenta mil anos de atraso...

Formidável! (MACHADO, 2002, p. 138-139).

As observações oriundas da telegrafia, escritas por Alcântara Machado, quando consideradas em sua totalidade, apontam para a acuidade do cosmopolitismo inconfundível dos anos 1920. As informações, não raro incompletas e insuficientes, encantavam mais pela sensação da diminuição das distâncias do que pelo seu conteúdo. No dia cinco de outubro de 1924, por exemplo, o autor anuncia, em telegrama emitido de Pequim, o uso de macacos na guerra civil travada na China. No dia dezesseis, indigna-se com a possível proibição, por parte do Papa Pio XI, dos romances de Anatole France e, logo em seguida, comenta sobre uma greve de fome veiculada em um telegrama de Lisboa. É a ênfase no processo e não no produto, característico, também, na arte cinematográfica dos primeiros tempos (MACHADO, 2002).

Além do telégrafo, movido pelas mesmas circunstâncias temporais, é criado, em 1887, o gramofone, de Berliner, que relima as imperfeições do fonógrafo de Edison de 1877, já que este lançava mão de um cilindro e não de discos achatados, formato que acabará por se consagrar na indústria fonográfica (CHALINE, 2014). Mais tarde, nas primeiras décadas do século XX, as vitrolas invadem residências e ambientes de socialização graças à sua portabilidade, como a câmera Pathé-Baby.

Em 1897, Marconi, servindo-se de descobertas esparsas, inventa o rádio, conhecido como o "telégrafo sem fios", casualmente no mesmo ano em que Underwood apresenta a máquina de escrever Underwood $\mathrm{n}^{\circ} 1$, principiando a era do teclado. Este último engenho trazia a singularidade de oferecer uma área de escrita visível, demarcando a abolição da escrita maquinal às cegas (CHALINE, 2014).

Já no começo dos 1900, Brownell apresenta a câmera fotográfica Kodak Brownie. Logo, ela se torna um sucesso comercial, motivado pela sua praticidade. Apesar de ser, inicialmente, destinada ao público infantil, a kodak conquistou, também, o público adulto.

Süssekind (2006, p. 30-39) depreende, com argúcia, o legado estético das kodaks relativo à tessitura literária. No subcapítulo Kodaks e ornatos, a teórica enceta sua história da técnica, na literatura brasileira, pela fotografia. Na sua visão, no alvorecer do século XX, os artistas começaram a se sentir mais à vontade para servir-se dos princípios mecânicos da câmera, "kodakando" a realidade por meio de um estilo verbal sintético, em instantâneos. Uma comprovação de extrema relevância na legitimação desse novo sistema narrativo 

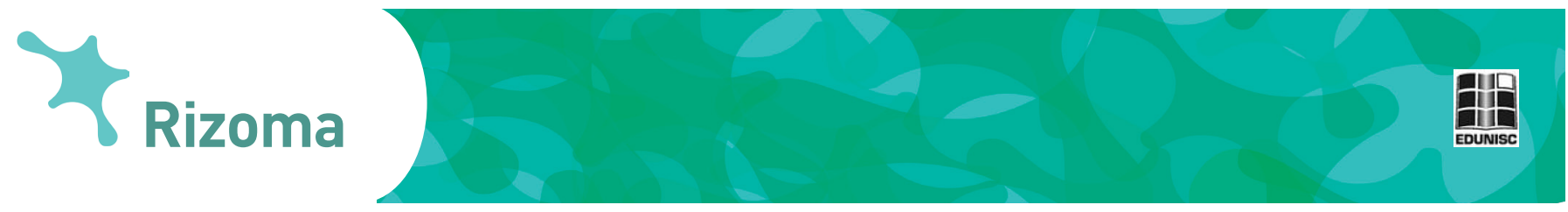

está na coluna Kodaks, de Kilkerry, que abre mão de subjetividades e ornatos, comuns no gênero crônica, para flagrar, em flashes, o mundo ao seu redor.

Süssekind (2006) estende a Alcântara Machado a "kodakização" da paisagem, em Pathé-Baby, selecionando um fragmento da obra. A passagem eterniza Paris, em instantâneos sucessivos, e enforma, literariamente, a técnica da máquina, recorrendo à uma prosa de feição concisa e entrecortada. O componente inóspito do trecho é o registro de um inglês que manipula uma Kodak. Dessa maneira, as barreiras entre a forma e o conteúdo se dissipam em prol de um objetivo estético bem definido:

\footnotetext{
Place de l'Étoile. Em torno do Arco do Triunfo magotes de automóveis giram. As avenidas são doze bocas de asfalto que comem gente e veículos, vomitam gente e veículos. Insaciáveis.

Ruído. Pó. E gente. Muita gente. O soldado apita, levanta o seu bastão, e a circulação para para que se possam passar, tranquilamente, a ama e seu carrinho. Duas costureirinhas que tagarelam. A família que vai bocejar nos bancos do Bois. Um maneta vendendo alfinetes. Gargalhadas de uma loura de olheiras verdes. A Kodak de um inglês. Um casal de namorados. Israelitas ostentando a roseta da legião de Honra. Monóculos. Paris que passa. (MACHADO, 2002, p. 49).
}

O fragmento de Paris, ainda que represente o estilo fotográfico, exibe, ao mesmo tempo, um acervo de apropriações linguísticas encontradas, com maior constância, na poesia. A personificação das avenidas que "engolem" e "vomitam" gente e veículos; as aliterações de "p", "r" e "s", colidindo as consoantes presentes no significante "Paris"; e as sinestesias auditivas provocadas pelas palavras "ruído", "gargalhadas" e "tagarelam" comprovam essa avaliação. Fazendo o método inverso e reunindo todas as partes, a engrenagem narrativa parece convergir para consolidar uma estética que traz consigo as técnicas das mídias surgidas na época, mas sem esquecer sua especificidade artística.

Em Bolonha, o autor repete a estratégia narrativa: "Do Piazzale dela Chies adi Michele in Bosco, kodaks britânicas retratam a cidade. A Torre Garisenda, velhinha cansada, inclina-se sobre a Asinelli, vertical audaciosa no azul" (MACHADO, 2002, p. 121). Mesmo sucinto, o trecho do capítulo se presta à uma análise minuciosa por conter, em si, alguns elementos conjugados de maneira criativa. Na passagem de Paris, a voz narrativa cita a Kodak de um britânico, e não o inverso, o britânico com uma Kodak, que soaria mais natural, denotativamente, postura linguística que coloca em relevo a câmera, e não o seu operador. Bolonha avança para o campo da linguagem figurada, posicionando 


\section{$\gamma_{\text {Rizoma }}$}

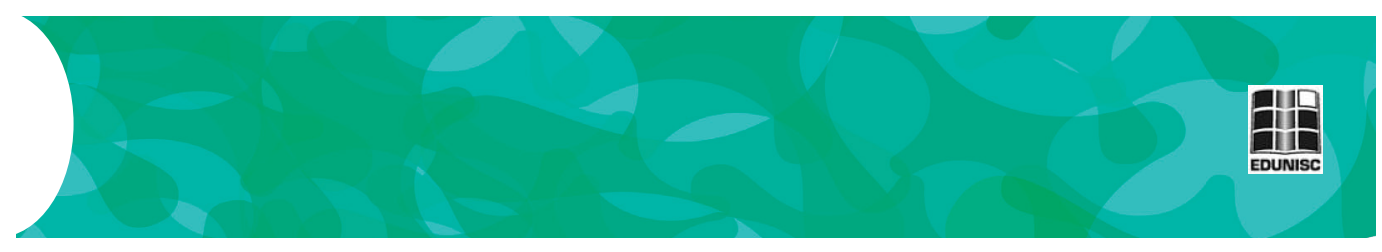

a máquina, sintaticamente, como sujeito da ação, capaz de retratar a cidade a partir dos meios automatizados que possui. E o resultado da fotografia é pura poesia. A histórica torre Garisenda, citada por Dante, na Divina comédia, é aproximada à imagem de uma velhinha exaurida que necessita do auxílio da outra, a Asineli, descrita com os adjetivos "vertical" "audaciosa", como se sustentasse a torre vizinha.

Ademais, a fotografia age em compasso afinado com a telegrafia. $\mathrm{O}$ instantâneo exigido pelo retrato sintoniza-se com a prosa coordenada da sintaxe telegráfica, velha conhecida do autor. E a objetividade, inerente a esse sistema de comunicação, não danifica a literariedade do texto, como Bolonha comprovou, mas, ao contrário, a agudiza pela economia vocabular, valorizando cada termo da oração. Oswald de Andrade, no prefácio de Memórias sentimentais de João Miramar, de 1924, anuncia a revolução da escrita modernista, liando, pela primeira vez, "o estilo telegráfico e a metáfora lancinante" (ANDRADE, 1980, p. 10).

Candido (CANDIDO; CASTELLO, 2006) enxerga, na literatura de Alcântara Machado, as sugestões da arte de Oswald de Andrade, e o considera mais espontâneo e comunicativo que o predecessor. $\mathrm{O}$ teórico também filia o autor de Pathé-Baby ao telegrafismo: "Cultivou uma prosa leve e bem-humorada, usando a palavra direta, ou dando o nome exato à coisas e objetos, enquanto a despojava de seus elementos de adorno, para reduzi-la a uma expressão telegráfica, sem ênfase" (CANDIDO; CASTELLO, 2006, p. 153).

Em Veneza, Alcântara Machado descreve as sensações de um passeio noturno realizado de gôndola. No Canal Grande, as memórias dos tempos passados, tão vivos, traz à sua sensibilidade detalhes liricamente narrados da literatura de Shakespeare, Byron e Musset e da música de Wagner em uma comunhão de referências intermidiáticas. Todas essas menções surgem, na comparação traçada pelo autor, "como mensagens soltas de T.S.F" (MACHADO, 2002, p. 100). A sigla T.S.F significa, simplesmente, "Telegrafia Sem Fios". Ora, tal comentário explicita o grau de importância que a comunicação telegráfica possuía na maneira de o escritor apreender as coisas ao seu redor, intensificando e legitimando as hipóteses levantadas.

Retomando Paris, a velocidade assume um protagonismo temático e formal que também é resultante do mesmo horizonte técnico. $\mathrm{O}$ conceito de celeridade difundiu-se a começar pelo advento do automóvel e do avião, ambos coetâneos e partícipes desse mesmo momento. Telles, ao pensar sobre o Futurismo, a vanguarda que se fundamentou na "beleza da velocidade", considera, também, a atuação que a rapidez exerce na literatura destes autores:

Assim, mais pelos manifestos do que pelas obras, o futurismo exaltou a vida moderna, procurou estabelecer o culto da máquina e da velocidade, pregando ao mesmo 

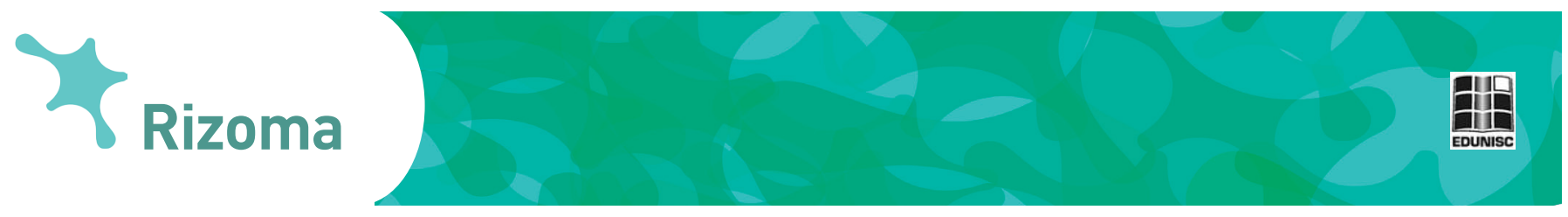

tempo a destruição do passado e dos meios tradicionais da expressão literária, no caso, a sintaxe: usando as palavras em liberdade, rompia a cadeia sintática e as relações passavam a se fazer através da analogia. (TELLES, 2012, p. 111).

Em maio de 1921, no Jornal do Comércio, Oswald de Andrade publica o texto "Meu poeta futurista", depois de ter lidos os originais de Pauliceia desvairada. Sem citar o nome de Mário de Andrade, ele escreve, telegraficamente, sobre a renovação da poesia paulistana que virá pelas ideias geniais desse "lívido e longo Parsifal conhecido pelo seu saber crítico" (ANDRADE, 1997, p. 225). O texto, como era de se esperar, causou furor entre os leitores, tanto pela provocação estilística de Oswald, que parodia o estilo futurista em uma mescla de gêneros, quanto pela ocultação da identidade do tal poeta, sugerindo apenas, com informações, quem seria o ousado escritor.

Isso explica o motivo de Mário ter rechaçado a classificação do amigo e companheiro de pena duas vezes, primeiramente no Jornal do Comércio e, depois, no Prefácio interessantíssimo da obra. $\mathrm{Na}$ apresentação, mesmo considerando possuir pontos de encontro com a vanguarda italiana, o poeta afirma que Oswald errou em defini-lo desta forma, apesar de assumir a culpa pelo ocorrido, já que havia lido o texto antes dele ter saído e, por vaidade, autorizara a publicação (ANDRADE, 2003).

Como prova dessa aproximação, em $A$ escrava que não é Isaura (ANDRADE, 2010), Mário vê como acertada a tentativa de os escritores imitarem a velocidade dos novos tempos na escrita: "Rapidez e síntese. Congregam-se intimamente. Querem alguns filiar a rapidez do poeta modernista à própria velocidade da vida hodierna. Está certo"(ANDRADE, 2010, p. 64). E, tratando da escrita telegráfica, conclui ser natural esta reprodução das novas formas de comunicação, delegando ao leitor a responsabilidade de compreendê-las:

\footnotetext{
A inteligência do poeta - o qual não mora mais numa torre de marfim - recebe o telegrama no bonde, quando o pobre vai à repartição, para a Faculdade de Filosofia, para o cinema. Assim virgem, sintético, enérgico, o telegrama dálhe fortes comoções, exaltações divinatórias, sublimações, poesia. Reproduzi-las! ... E o poeta lança a palavra no papel. É o leitor que deve-se elevar à sensibilidade do poeta não é o poeta que se deve baixar à sensibilidade do leitor. Pois este traduza o telegrama! (ANDRADE, 2010, p. 18).
}

Porém, desse imenso universo técnico que se avultava, a mais relevante invenção da época foi o cinematógrafo. Afinal, o cinema foi e é uma das expressões estéticas que melhor conseguem unificar a arte e a cultura de massa, desencadeando, desde o seu início, um 


\section{$\gamma_{\text {Rizoma }}$}

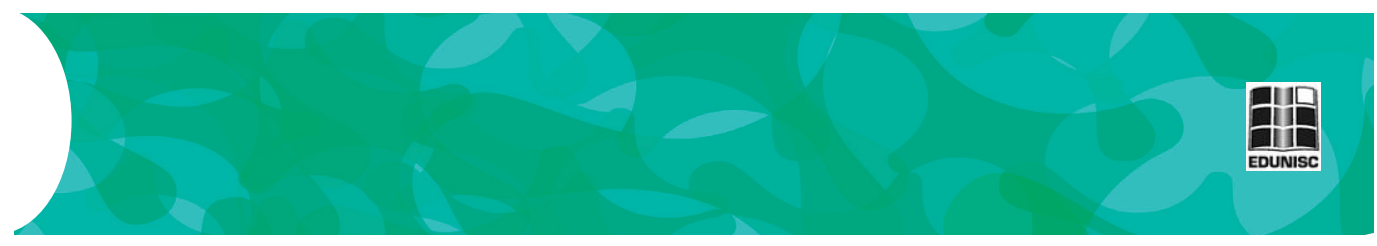

alvoroço nas multidões. E foi com base neste instrumento que Alcântara Machado arquitetou o projeto estético-literário de Pathé$B a b y$, aproximando imagens, letras e sugestões sonoras com maestria de quem conhecia as artes e as mídias.

O cinema, assim como a maioria das mídias, surgiu como um processo técnico e evolutivo que se serviu de experimentos anteriores, melhorando problemas, defeitos e inadequações de outros aparelhos. O mais conhecido antecessor do cinematógrafo foi o já citado cinetoscópio, de Edison, de 1891. A novidade agitou não só os Estados Unidos e a Europa, mas também o Brasil, impressionando pelas imagens reproduzidas e, em especial, pela fita que era movida por um motor de vinte volts (SÜSSEKIND, 2006).

A maior falha dessa máquina, contudo, era a impossibilidade de transformar a exibição das imagens em experiência compartilhada, pois admitia apenas um espectador por vez em cada cinescópio. Corrigindo essa pequena imperfeição, o francês Bouly criou o Cynématographe León Bouly, capaz de capturar imagens em movimento e, posteriormente, projetá-las em uma tela. Como Bouly não tinha recursos financeiros para comercializar a sua criação, ou sequer aperfeiçoá-la ou patenteá-la, ele vendeu-a aos verdadeiros pais da Sétima Arte: os irmãos Lumière (CHALINE, 2014).

Auguste e Louis Lumière adquiriram o cynématographe de Bouly e o estudaram à fundo, detectando erros e otimizando virtudes. E, em 1895, voilà: o cinematógrafo é apresentado como a mais nova sensação técnica. Rosenfeld (2002), explica a significância da automação e dos fatores econômicos na história do cinema:

\footnotetext{
O historiador da pintura não precisa contar a história dos pincéis, telas e as diversas descobertas químicas que permitiram a produção de tintas e materiais adequados. Trata-se de momentos indispensáveis, mas completamente subordinados. Os elementos técnicos do cinema, porém, na sua estreita interdependência com os fatores econômicos envolvidos, revestem-se de tamanha importância que não é possível suprimi-los. (ROSENFELD, 2002, p. 52).
}

Segundo Lanzoni (2005), o cinematógrafo dos irmãos Lumière era uma câmera, equipada com uma manivela, de 7,25 quilos, o que a tornava portátil, podendo ser levada à diferentes ambientes. Sua composição e funcionamento permitiam tarefas múltiplas que incluíam filmagem, impressão e projeção de filmes. Posto isto, o cinegrafista poderia concluir um trabalho em apenas um dia: realizava a filmagem pela manhã, processava-a à tarde e a exibia, para uma plateia, à noite.

Chaline(2014) avalia as questões mecânicas do modo de filmagem realizado no cinematógrafo. $\mathrm{O}$ operador deveria girar a manivela duas vezes por segundo a fim de passar a película cinematográfica pelo 
obturador a uma velocidade de dezesseis quadros no mesmo tempo. Este padrão rítmico prevaleceu ao longo das três primeiras décadas do cinema, durante a vigência do cinema-mudo. Mais tarde, a velocidade foi aumentada para vinte e quatro quadros, modelo usado até hoje.

Apesar de o cinematógrafo dos irmãos Lumière apresentar algumas limitações técnicas, como suportar apenas filmes de baixa metragem e ter uma dependência muito grande em relação à luminosidade dos ambientes, ele trazia consigo, também, uma inovação notável: o came excêntrico. Patenteado por Auguste e Louis, esse mecanismo transformava a rotação - acionada pela manivela - em movimento vertical, facilitando a passagem do filme pelo obturador. O came ficava preso a um suporte e os dois pinos embutidos em sua estrutura atravessavam os furos do filme, fazendo-o mover-se a exatos dezesseis quadros por segundo.

Afora estas particularidades, a real magia despertada pelo cinema, na comparação com as outras artes, decorre de uma ilusão óptica igualmente gerada pela técnica. Quando uma pessoa assiste a um filme, os vinte e quatro fotogramas (dezesseis no cinema mudo), projetados em apenas um segundo, não são identificados individualmente, mas em conjunto. Assim, as interseções da película passam desapercebidas, fazendo com que a sensibilidade visual acompanhe um movimento contínuo de imagens justapostas.

O encanto sinestésico, estimulado por esta manobra de caráter ilusionista, acarretou, na primeira sessão cinematográfica pública, uma mescla de arrebatamento e desordem entre os espectadores. Em acordo com Rosenfeld (2002) e Chaline (2014), no dia vinte e oito de dezembro de 1895, no porão do Grand Café, em Paris, foram projetados dez filmes de trinta a cinquenta segundos cada que causaram grande alvoroço.

As películas, chamadas de protodocumentários, evidenciavam a tentativa de representar a agitação da vida moderna, como fica bastante claro em $A$ saída dos operários da Fábrica Lumière e A chegada do trem à estação. Este último, em especial, assustou as pessoas da plateia, que, confundindo projeção de imagem e realidade, levantaram de seus assentos, temendo que o trem em movimento pudesse atingi-las.

Ocorre que os próprios Lumière se desinteressaram pela nova arte. Eles a viam apenas como curiosidade científica e jamais vislumbraram sua potencialidade comercial. Rosenfeld (2002) atribui a isso o fato de Auguste não aceitar vender o aparelho ao técnico de espetáculos Méliès que, pensando justamente o contrário, estava animado em explorar os seus recursos. Além da recusa, Lumière ainda teria o aconselhado a investir o seu trabalho em outro ramo, visto que, na sua visão, o cinematógrafo já havia alcançado o seu apogeu e, em pouco tempo, seria esquecido. 


\section{$\gamma_{\text {Rizoma }}$}

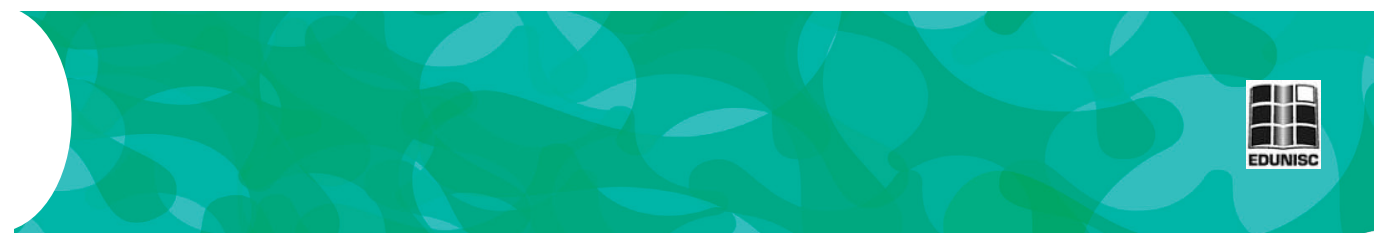

Para Rosenfeld (2002), Méliès foi o responsável por elevar a projeção de imagens à condição de arte cinematográfica. Após a malograda proposta aos Lumière, o técnico construiu seu próprio aparelho e rodou os primeiros filmes de sua autoria, angariando um público de mais de mil e quinhentos espectadores por dia. Em 1907, ele descobriu, por acaso, um truque simples, mas de resultado poderoso. Ao manusear uma câmera com problemas operacionais, Méliès percebeu que alguns fotogramas danificados faziam com que algumas imagens sumissem, dando lugar a outras que apareciam, como em um passe de mágica. Trabalhando conscientemente com o recurso, Méliès criava o "truque por substituição", um dos efeitos especiais mais genuínos da história do cinema.

A partir de Méliès, e de muitos outros que experimentaram os limites da representação fílmica com o passar dos anos, o cinema foi se desenvolvendo por dois caminhos, a saber: a) a documentação visual e irrestrita da realidade, com a captação de imagens que, através da montagem, redefinem os conceitos de espaço e tempo e; b) a busca pela narratividade, com histórias ficcionais que impliquem a encenação de papéis, encadeando cinema, teatro, literatura e, por que não, música, pelo acompanhamento sonoro dos filmes que não demoraram muito a surgir.

As fronteiras entre as duas possibilidades são tênues e, frequentemente, difíceis de definir. Bresson (2008) sumariza a querela definindo

\footnotetext{
dois tipos de filmes: aqueles que utilizam os recursos do teatro (atores, encenação, etc.) e se servem da câmera com o intuito de reproduzir; aqueles que utilizam os recursos do cinematógrafo e se servem da câmera com o intuito de criar. (BRESSON, 2008, p. 19).
}

Ainda que a complexidade da questão permaneça, Bresson obtém o mérito de trazer para o debate teórico a dicotomia "reproduzir X criar", extremamente pertinente ao contexto cinematográfico, mormente, às suas primeiras décadas. A fim de distingui-las, o autor pormenoriza os termos "cinema" e "cinematógrafo", preferindo o segundo em detrimento do primeiro. Bresson considerava "cinema" a reprodução, por meio da projeção da imagem, do teatro, não acrescentando, em nada, ao campo da arte. Cinematógrafo, em contrapartida, significaria a elaboração de uma linguagem nova, que se molda às especificidades do código audiovisual, transbordado de criatividade.

O uso corrente, entretanto, evidenciava justamente o oposto. A expressão "cinematógrafo", muito comum no início do século, geralmente designava o cinema construído sem muita finalidade estética, em associação direta com a máquina patenteada pelos irmãos Lumière, enquanto que a palavra "cinema" começou a se projetar 
na consequente afirmação da técnica como realização artística. Cinematógrafo, além disso, designava as salas de cinema, como a passagem Assis, do Pathé-Baby, revela. Na visita à Chiesa Superiore, o guia comenta a semelhança da cripta à uma sala de espera: "Sembra la sala d'aspett di un cinematografo"" (MACHADO, 2002, p. 162).

Além dessas atribuições, o cinema passou a desempenhar, conjuntamente, uma função atrelada ao jornalismo. Rosenfeld (2002) descreve, com detalhes, essa nova incumbência, arquitetada, originalmente, pela Pathé Frères:

Foi em 1908 que Charles Pathé resolveu organizar cenas da vida atual, editando-as num filme periodicamente distribuído. Toda semana apresentar-se-ia, assim, ao público, um panorama dos acontecimentos mais sensacionais. (ROSENFELD, 2002, p. 94).

Dois anos depois da inauguração, o Pathé-Journal fazia um sucesso estrondoso. Aproveitando o desenvolvimento da seara lucrativa, surgem o Gaumont-Jornal e o Éclair-Journal. O novo padrão é tão bem recebido pelo mundo afora que outros países adotam a mesma estratégia, dissolvendo, em parte, as barreiras limítrofes entre os territórios e diminuindo as distâncias do globo. Em 1911, segundo Rosenfeld (2002), em ocasião do coroamento de George V, na Inglaterra, quatorze cinejornais da França registraram o evento, consumindo três mil quilômetros de filme, a sua maioria revelados nos trens enquanto os jornalistas retornavam para Paris.

Hobsbawm (2015), em A invenção das tradições, alega que, conquanto "nada pareça mais antigo e ligado a um passado imemorial do que a pompa que cerca a realeza britânica" (HOBSBAWM, 2015, p. 7), ela existe, na sua forma atual, desde fins do século XIX e início do XX. Cannadine (2015), no mesmo livro, enumera dez razões que influíram nas transformações dos rituais da Grã-Bretanha. Duas delas são condicionadas pela interferência dos meios de comunicação e transporte, sendo que uma, em especial, diz respeito diretamente ao que Rosenfeld menciona. O quarto aspecto é o tipo, alcance e posicionamento dos meios de comunicação: com que vivacidade a imprensa descrevia os fenômenos da realeza, e qual é a imagem que ela transmitia da monarquia?

Pathé-Baby, mimetizando, verbalmente, os registros documentais formatados e rodados em cinematógrafos, descreve uma aparição pública de George V no Hotel Savoy. O excerto, que integra o capítulopelícula Londres, é uma demonstração literária evidentemente dessa nova maneira de a família real interagir com o público.

Atento a todos os detalhes, o narrador pontua o cosmopolitismo do evento, ou "angu internacional", nas palavras do autor, composto
${ }^{2}$ Parece a sala de espera de um cinematógrafo (Tradução nossa). 


\section{$\gamma_{\text {Rizoma }}$}

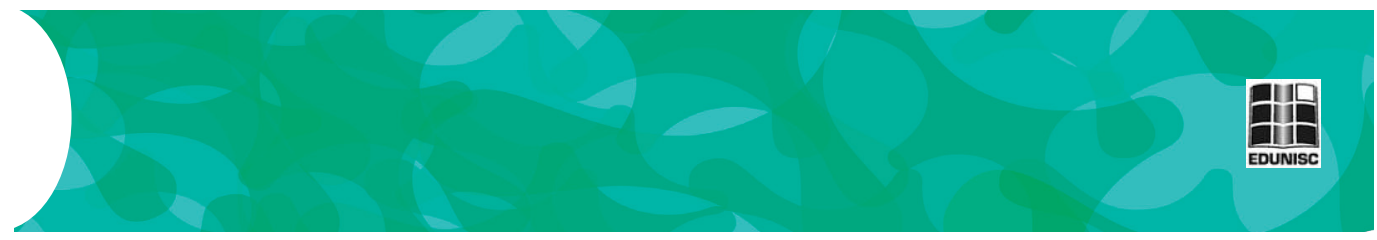

por japoneses, italianos, argentinos e até persas, comprovando o interesse dos estrangeiros em relação aos assuntos da monarquia inglesa, também citado por Cannadine (2015). A presença brasileira também é garantida no episódio, primeiramente, pelo cinejornalismo literário de Alcântara Machado, bem como pela ópera O Guarany, de Carlos Gomes, que é executada no salão de chá do hotel e reproduzida pelo narrador por onomatopeias:

\footnotetext{
O saguão rubro-azul do Savoy Hotel é uma aula da escola Berlitz. Os elevadores sobem argentinos e descem japoneses. Cartolas cinzentas. Angu internacional. Polainas brancas. Dois persas pedem Apollinaris em francês. Sujeitos de fraque pedem gorjetas. Inglêsas sardentas. Com exagero. O tenor italiano faz barulho. Cartões postais. Fardas da Agência Cook. Fumo. O porteiro comanda. Pela porta do salão de chá as notas do Guarany (tan-tan-tararam tan-tararam) entram, perdemse. Todos levantam-se. Precipitam-se. Correm. Os homens dos automóveis:

- The King! (MACHADO, 2002, p. 80-81).
}

No Brasil, naturalmente, o processo de aceitação do cinematógrafo sucedeu-se de forma tardia e gradual, encontrando, mais uma vez, a resistência da inteligência institucionalizada, representada, nas palavras de Sevcenko (2014, p. 96), pelos "mosqueteiros intelectuais". O grupo, formado pelos acadêmicos que viriam a ser criticados pelos modernistas, cujo maior expoente era Bilac, mostrava-se perseverante e não admitia a inclusão de novas formas de expressão nem mesmo no jornal.

Em 1908, o poeta discute a repercussão de uma notícia que aventava a possibilidade de o cinematógrafo despertar doenças variadas, como epilepsia, distúrbios mentais e epidemias. Ele se mostra descrente em relação aos boatos, mas afirma: "A única e formidável acusação que se pode fazer a esta mania moderna é outra: é a de estar contribuindo poderosamente para viciar e apodrecer a pobre língua portuguesa, tão digna de melhor sorte (BILAC, 2008, p. 206-207).

Bilac assumiu a coluna no Gazeta de notícias, no ano de 1897, com o desafio de substituir Machado de Assis. Sua reputação, na época, era ótima e seu trabalho como poeta parnasiano tinha reconhecimento de crítica e público. O livro Vossa insolência, organizado por Dimas (2008), é uma seleta desses textos que versam sobre temas diversos e que, vistos hoje, compilam os pensamentos da então classe letrada fluminense.

Da antologia, duas crônicas se sobressaem, além da já destacada acima, por realçar: primo, o modo pejorativo com que o príncipe dos poetas recebe a fotografia como parte integrante do jornalismo e; secundo, a cinematografia, que se multiplicava, popularmente, pelos bairros da 

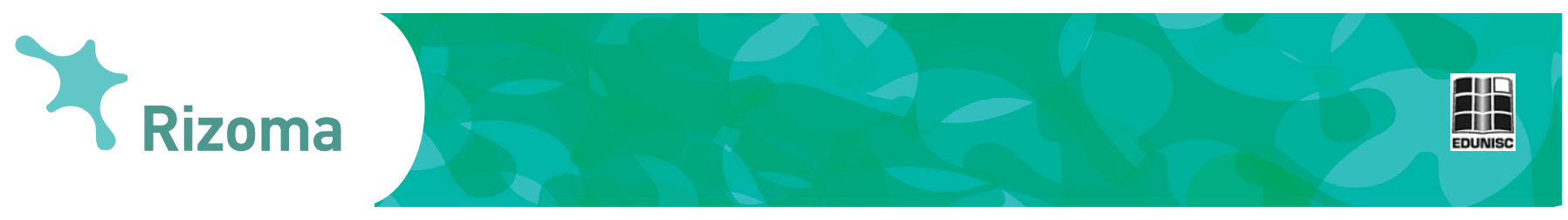

capital. Em Fotojornalismo, de 1901, Bilac prevê o extermínio da escrita pelo desenho em um mundo que cultua, com um fervor crescente, a imagem e a velocidade. O tom é de um exagero catastrófico:

\begin{abstract}
Vem perto o dia em que soará para os escritores a hora do irreparável desastre e da derradeira desgraça. Nós, os rabiscadores de artigos e notícias, já sentimos que nos falta o solo debaixo dos pés... O exército rival vem solapando os alicerces em que até agora assentava a nossa supremacia: é o exército dos desenhistas, dos caricaturistas e dos ilustradores. O lápis destronará a pena: ceci tuera cela. (BILAC, 2008, p. 165).
\end{abstract}

Não atenuando o impacto de mais de duas décadas que separa a crônica de Bilac da prosa vanguardista de Alcântara Machado, PathéBaby pode ser considerada uma das comprovações - quem sabe a mais radical enquanto obra literária - que os modernistas souberam aproveitar o manancial sígnico proposto pelos veículos que surgiam ou que se reinventavam, como no caso específico da imprensa jornalística.

O segundo texto é ainda mais elucidativo nesse sentido. Moléstia da época, de 1907, clarifica a opinião de Bilac em relação às sessões cinematográficas que estavam seduzindo, de maneira progressiva, os habitantes do Rio de Janeiro. A crônica trata da incursão do poeta por dezoito cinematógrafos, instado por um conhecido que, na sua visão, está completamente corrompido pelo vício dos novos tempos. Entretanto, é, no mínimo, intrigante a maneira com a qual a descrição negativa do poeta pode ser comparada, em termos de temática, com a prosa de Alcântara Machado:

\footnotetext{
A minha viagem durou duas horas: entretanto, em tão escasso tempo achei meio de ver meio mundo: estive em Paris, em Roma, em Nova York, em Milão; vi Cristo nascer e morrer; desci ao fundo de uma mina de carvão; estive ao lado de um faroleiro, no alto de um farol, entre os uivos das ondas; assisti ao tumulto de uma greve na França; vi o imperador Guilherme passar revista no exército alemão na Westfália; Vi Sansão ser seduzido e vencido por Dalila, e sepultar-se sob as ruínas do templo derrocado...

Creio que já todos terão compreendido que esta longa viagem foi... cinematográfica. (BILAC, 2008, p. 195-196).
}

A tarefa, embora curta, o deixa "moído", "derreado", "tonto". A "moléstia da época" fascina o artista com um turbilhão de imagens, um tanto desconexas, que desafiam os sentidos, comprimindo, em um curto espaço de tempo, um caleidoscópio multifacetado de experiências. Hauser (1995), refletindo sobre essas questões espaçotemporais que definem a realidade do homem do século XX, aponta o efeito causado pela "era do cinema" como um maravilhamento da 


\section{$\gamma_{\text {Rizoma }}$}

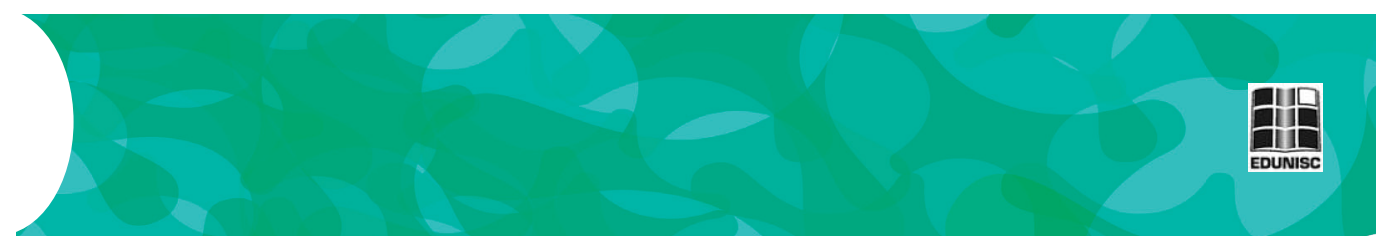

consciência concentrada no tempo presente, da mesma forma que o universo sobrenatural marcava a Idade Média e a esperança do futuro, o Iluminismo. Essa realização dos eventos aglutinados, que se multiplicam em tempo real, cria uma nova concepção de tempo que (des)norteia o sujeito e forja as suas relações sociais.

Benjamin (2012), em A obra de arte na época de sua reprodutibilidade técnica, de 1935, conclui que, relativo à cada período histórico, estão circunscritos o modo de vida das coletividades humanas e suas consequentes formas de percepção. Intimamente ligada à sensibilidade da sociedade mecanizada do contexto entre guerras, o teórico detecta, como uma consequência cultural de fácil identificação, a decadência do que ele chama de "aura" da obra de arte. O conceito de aura, também presente em Pequena história da fotografia, de 1931, e Sobre alguns temas de Baudelaire, de 1939, com algumas variações, é definido, aqui, como um tecido estreito de espaço e tempo, dotado de singularidade: "aparição única de uma distância, por mais próxima que seja (BENJAMIN, 2012, p. 27).

Em Pathé-Baby há uma passagem muito clara sobre a reprodutibilidade da obra de arte. Em Roma, envoltos à devoção cristã, os ingleses adquirem uma cópia colorida da Batalha de Ostia, afresco de Rafael que orna uma das salas do Museu do Vaticano:

Os ingleses - coitados - enegrecem de notas graves os Baedeckers vermelhos no pó da Domus Flavia, deante do Juizo Final, da Capela Sixtina, à luz das velinhas na escuridão frigorificadas catacumbas de S. Calixto, e levam para enquadrar na Inglaterra uma reprodução colorida da Batalha de Ostia, da Torre Borgia. (MACHADO, 2002, p. 170).

Benjamin demarca duas circunstâncias especiais que catalisaram a derrocada da aura na primeira metade do século $\mathrm{XX}$, ambas diretamente envolvidas com o crescimento das massas e a intensidade de seus movimentos. A primeira entende que "trazer para mais próximo" de si as coisas é igualmente um desejo apaixonado das massas de hoje, como o é a tendência desta de suplantar o caráter único de cada fato por meio da recepção de sua reprodução" (BENJAMIN, 2012, p. 29). E a segunda, que inclui a técnica e sua capacidade de reproduzir produtos, imiscui duração e unicidade, advertindo o caráter efêmero que a arte começa a desempenhar:

E, de modo inconfundível, a reprodução, tal como fornecida pelos jornais ilustrados e noticiários semanais cinematográficos, se diferencia da imagem. Unicidade e duração encontram-se tão estreitamente imbricadas nesta como fugacidade e repetibilidade naquela. $\mathrm{O}$ despojamento do objeto do seu invólucro, a destruição da 


\section{$\gamma_{\text {Rizoma }}$}

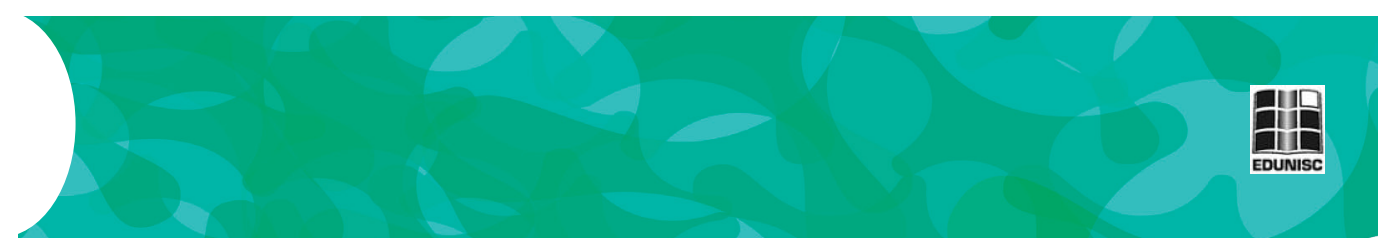

aura, é a característica de uma percepção, cujo "sentido para o igual no mundo" cresceu tanto que por meio da reprodução também o capta no que é único. (BENJAMIN, 2012, p. 30-31).

Bilac talvez seja, dentre os escritores vivos no prelúdio do século passado, o que concebeu, com maior intensidade, cada obra de arte como um produto valioso e irrepetível. O poema "Profissão de fé", aula metalinguística sobre os métodos meticulosos do parnasianismo ars gratia artis, compara o fazer poético com o trabalho de ourivesaria, com o objetivo comum de se chegar a um resultado material, seja uma joia ou um poema, que represente a beleza.

Essa obsessão estética dos parnasianos trouxe aos círculos literários um retorno à cultura greco-romana, considerada por Benjamin como antítese perfeita dos "tempos modernos". Uma vez que os princípios clássicos preconizam, pela arte, valores eternos, nos quais a aura instala-se pelas veredas da raridade e da unidade, a técnica, na contramão, permite a depuração sistemática da obra, abrindo espaço para edição e a montagem. Assim, a aura, pela reprodução, deixa de fazer sentido, extinguindo-se, enquanto que a arte passa a ganhar o sinal distintivo da perfectibilidade, podendo ser aperfeiçoada ilimitadamente.

Por estar justamente em conúbio com esse novo horizonte técnico que se descortina, Alcântara Machado se filia a esse conjunto de autores preocupados em compreender os adventos técnicos desse contexto inovador. E, assim, traz para o universo da literatura - e seus próprios mecanismos - o que há de mais significativo dessa nova maneira de entender a realidade que nos circunda.

\section{Referências}

ANDRADE, Mário de. A escrava que não é Isaura. Rio de Janeiro: Nova Fronteira, 2010.

ANDRADE, Mário de. Pauliceia Desvairada. In: SCHWARTZ, Jorge (org.). Caixa modernista. São Paulo: EDUSP/Imprensa Oficial; Belo Horizonte: Ed. da UFMG, 2003.

ANDRADE, Oswald de. Obras completas II: Memórias sentimentais de João Miramar Serafim Ponte Grande. Rio de Janeiro: Civilização Brasileira, 1980.

ANDRADE, Oswald de. Futurista?! In: BRITO, M. da S. História do Modernismo Brasileiro: I. Antecedentes da Semana de Arte Moderna. Rio de Janeiro: Civilização Brasileira, 1997. p. 234-8. 


\section{$\gamma_{\text {Rizoma }}$}

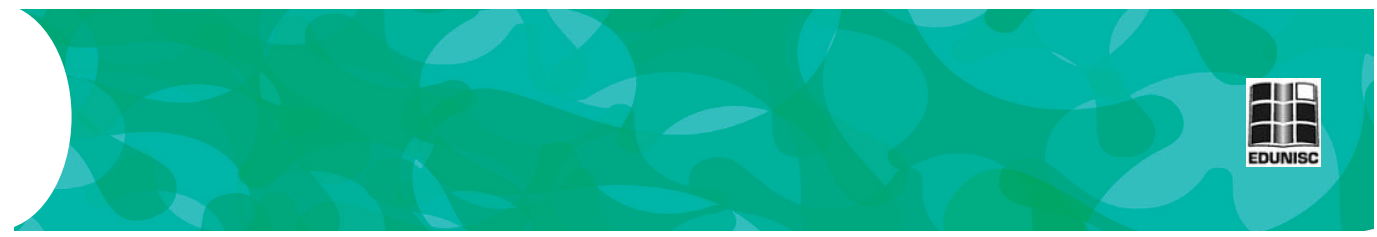

BENJAMIM, Walter. A obra de arte na era de sua reprodutibilidade técnica. Porto Alegre: Editora Zouk, 2012.

BILAC, Olavo. Vossa insolência. Companhia das Letras. São Paulo: Companhia das Letras, 2008.

BRESSON, Robert. Notas sobre o cinematógrafo. Tradução de Evaldo Mocarzel. São Paulo: Iluminuras, 2008.

CANDIDO, Antonio; CASTELlO, José Aderaldo. Presença da literatura brasileira: história e crítica. Rio de Janeiro: Bertrand Brasil, 2006.

CANNADINE, David. Contexto, execução e significado do ritual: a monarquia britânica e a "invenção da tradição". In: HOBSBAWM, Eric J.; RANGER, Terence (orgs). Tradução de Celina Cardim Cavalcanti. A invenção das tradições. São Paulo: Paz e Terra, 2015.

CHALINE, Eric. 50 máquinas que mudaram o rumo da história. Tradução Fabiano Morais. Rio de Janeiro: Sextante, 2014.

DIMAS, Antônio. Introdução. In: BILAC, Olavo. Vossa insolência. Companhia das Letras. São Paulo: Companhia das Letras, 2008.

HAUSER. Arnold. História social da arte e da literatura. São Paulo: Martins Fontes, 1995.

HOBSBAUWN, Eric; RANGER, Terence (orgs). A invenção das tradições. Tradução Celina Cardim Cavalcanti. São Paulo: Paz e Terra, 2015.

LANZONI, Rémi Fournier. French cinema: from its beginnings to the present. Nova Iorque: The Continuum International Publishing Group Inc, 2005.

MACHADO, António de Alcântara. Pathé-Baby: edição fac-similar comemorativa dos 80 anos da Semana de Arte Moderna (1922-2002). Belo Horizonte/Rio de Janeiro: Livraria Garnier, 2002.

PELLEGRINI, Tânia. Narrativa verbal e narrativa visual: possíveis aproximações. In: PELLEGRINI, Tânia (org.) et al. Literatura, Cinema e Televisão. São Paulo: Editora SENAC/Itaú Cultura, 2003. 


\section{$7_{\text {Rioma }}$}

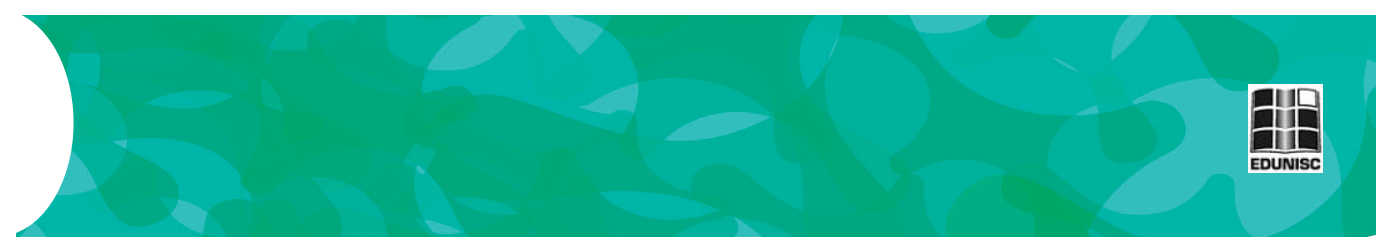

ROSENFELD, Anatol. Cinema: arte \& indústria. São Paulo: Editora Perspectiva, 2002.

SEVCENKO, Nicolau. Literatura como missão: tensões sociais e criação cultural na Primeira República. São Paulo: Companhia das Letras, 2014.

SUSSEKIND, Flora. O cinematógrafo de letras: literatura, técnica e modernização no Brasil. São Paulo: Companhia das Letras, 2006.

TELES, Gilberto Mendonça. Vanguarda Europeia \& Modernismo

Brasileiro: apresentação e crítica dos principais manifestos vanguardistas. Rio de Janeiro: José Olympio, 2012.

\section{Avaliadores: \\ Demétrio Soster \\ Eunice Piazza Gai}

